Running head: IDEOLOGICAL SYMMETRY

Sacralizing Liberals and Fair-Minded Conservatives: Ideological Symmetry in the Moral Motives in the Culture War

\author{
Jeremy A. Frimer ${ }^{1}$, Matt Motyl ${ }^{2} \&$ Caitlin E. Tell $^{1}$ \\ ${ }^{1}$ University of Winnipeg \\ ${ }^{2}$ University of Illinois, Chicago
}

Article published in Analyses of Social Issues and Public Policy and may be cited as:

Frimer, J., Motyl, M., \& Tell, C. (2016). Sacralizing liberals and fair-minded conservatives: Ideological symmetry in the moral motives in the culture war. Analyses of Social Issues and Public Policy.

\title{
Acknowledgements
}

We thank Nicola K. Schaefer and Ari Decter-Frain for their valuable contributions to studies 1 and 3, and we thank Jonathan Haidt for helpful comments. This research was prepared with support from a Social Sciences and Humanities Research Council (SSHRC) of Canada research grant to Jeremy Frimer [435-2013-0589].

Correspondence concerning this article should be addressed to Dr. Jeremy Frimer, Department of Psychology, University of Winnipeg, 515 Portage Avenue, Winnipeg, Manitoba, R3B 2E9. Email: j.frimer@uwinnipeg.ca 


\begin{abstract}
Political arguments may endure seemingly into perpetuity because the conflicted combatants view the issues in different ways, with one side decrying unfairness and the other side decrying attacks on the sacrosanct. We tested whether both conservatives and liberals rely on protecting the sacrosanct when justifying their attitudes on some contentious moral issues. In 4 studies, we examine how liberals and conservatives justify their political attitudes on the issues of same-sex marriage and the Keystone XL oil pipeline. Liberals supported same-sex marriage rights primarily in the name of fairness and equality; conservatives primarily opposed same-sex marriage rights as a matter of protecting the sanctity of traditional marriage. Symmetrically, liberals primarily opposed the development of the Keystone XL oil pipeline as a matter of protecting the sanctity of the Earth; conservatives supported the development of the pipeline as a matter of promoting fairness (e.g., corporate rights; as well as citing economic and foreign policy implications). Like conservatives, liberals also bring sacred thinking to moral issues. The culture war is mired in stalemate partly because each side considers some matters to be sacrosanct, and other matters as suitable for revision in the name of fairness.
\end{abstract}

Keywords: morality, moral foundations, political attitudes, ideology, sacredness 


\section{Sacralizing Liberals and Fair-Minded Conservatives: Ideological Symmetry in the Moral Motives in the Culture War}

Liberals and conservatives in the U.S. disagree bitterly about same-sex marriage laws and environmental regulations. As part of the ongoing Culture War, ideological battles such as these have resulted in legislative stalemates in government. We suggest that these sorts of issues are resistant to dialogue and compromise because liberals and conservatives think about the issues differently, and at times, use qualitatively different moral foundations to base their opinions. Not only do liberals and conservatives systematically disagree on whether the laws concerning marriage ought to change, they also disagree about why the laws should either stay the same or change. To conservatives, traditional marriage is sacrosanct, and ought not be altered. As a result, they denounce same-sex marriage as a desecration. Thinking of marriage as a secular institution that serves a societal purpose, liberals support the legalization of same-sex marriage on the grounds that it promotes fairness.

We suggest that sacred thinking is not limited to political conservatives. While conservatives sacralize traditional marriage, liberals sacralize the environment. In four studies, we present evidence that liberals and conservatives use different moral foundations in intransigent ideological debates, and, in important ways, trade moral languages when shifting debates from same-sex marriage to environmentalism. Studies 3 and 4 are the first to show that liberals can use sanctity more than conservatives when justifying their political attitudes on some Culture War issues.

\section{Different Kinds of Morality}

If the purpose of the law is to apply a set of rules about acceptable behavior in a fair and equal manner, its default moral logic should be fairness and justice (Rawls, 1971). By this 
reasoning, when people discuss legal matters, they ought to concern themselves with individual rights, equal opportunity, justice, and due process. However, fairness is not the only type of moral thinking that people may bring to discussions about the law. In particular, when a group of people perceives a legal change as a threat to something they hold dear, they may oppose the change using a qualitatively different kind of moral thinking - the foundation of sanctity.

Moral Foundations Theory (MFT; e.g., Graham, Haidt, \& Nosek, 2009; Graham et al., 2013; Haidt, 2007) suggests that morality is comprised of multiple distinct moral foundations: care, fairness, loyalty, authority, and sanctity. Past research has shown that liberals and conservatives rely on these moral foundations to different degrees; compared to liberals, conservatives tend to rely more on sanctity (and loyalty and authority), and less on fairness (and care; Graham et al., 2009). Individual differences in concerns about sanctity predict attitudes on an array of issues, such as abortion, euthanasia, and pornography (Koleva, Graham, Iyer, Ditto, \& Haidt, 2012) and candidate endorsement in the 2012 U.S. Presidential election (Franks \& Scherr, 2015). Moral foundations also explain individual differences in political involvement. Among liberals, individual differences in care and fairness foundations predict intentions to vote; the same pattern holds for conservatives with loyalty, authority, and sanctity (Johnson et al., 2014). MFT may also help explain why some debates, such as same-sex marriage, are so heated: conservatives may decry same-sex marriage as a threat to the sacrosanct institution of marriage whereas liberals may think about same-sex marriage in terms of fairness and rights.

\section{Do Liberals Rely on Sacred Thinking Too?}

We suggest that conservatives are not the only ones who revere and defend the sacrosanct. Liberals may rely on purity and sanctity-based thinking, too. Haidt (2010) raised the possibility that liberals have their own sacred values: 
Conservatives, particularly religious conservatives, live in a more sacralized world. Liberals, particularly secular scientifically-minded liberals, live in a more materialist, unmagical world. Yet [some evidence of sanctity] can be seen in the way the left treats environmental issues and the natural world as something sacred, to be cared for above and beyond its consequences for human—or even animal—welfare.

Liberals may sacralize objects and practices because sacralizing serves a social function - it binds group members to the cause (Durkheim, 1995/1915; Haidt, 2012; Smith, 1976/1759). By elevating an object or practice from the realm of the mundane into the realm of the sacred, the entity takes on a "transcendental significance that precludes comparisons, tradeoffs, or indeed any mingling with secular values" (Tetlock, 2003, p. 320). For example, Hindus sacralize the cow, prohibiting its consumption.

Sacred values may send a high fidelity signal about an individual's loyalties. Respecting the integrity of a sacralized entity can demand self-sacrifice (for Hindus, foregoing a readily available food source). Inasmuch as sacred values also tend to be bizarre and outlandish to outgroup members (e.g., worshipping a cow; Atran \& Norenzayan, 2004), ingroup members treat the object in a way that no rationally acting outgroup member would. Showing respect for a sacred practice signals to others one's social identity and confers upon the adherent ingroup status (Sachdeva \& Medin, 2009) and the benefits of group membership. Supposing that sacralization is an adaptation that helps individuals bind together into cooperative units, then the practices should be evident in any functioning moral community — be it on the political Right or Left. Based on this social functionalist reasoning, we predict that sacralization may be ideologically symmetric. Both the political Left and Right may sacralize.

When a group holds an entity to be sacred, alterations to that entity will be met with moral condemnation and sanctity-based rhetoric. In contrast, if the entity under consideration is not sacred to an individual, then individuals will likely consider changes to laws using costbenefit revisionism in the name of fairness (Tetlock, 2003). Applied to the issue of same-sex 
marriage, we predict that conservatives will respond primarily with condemnation and sanctitybased arguments to ward off the threat to the sacred institution of traditional marriage; liberals will primarily respond with fairness-based arguments to ward off the threat of inequality in access to a major societal institution.

Theorists (e.g., Rottman, 2014) have raised the possibility that liberals bring purity/sanctity thinking to environmental issues. And, Koleva et al. (2012) found that individual differences in the purity foundation predicted attitudes about global warming intervention, independent of political ideology. A recent study (Frimer, Tell, \& Haidt, 2015) found that liberals use sanctity in their moral thinking in opposition to environmental damage. The previous study, however, examined liberal mountain climbers' reactions to the flagrant desecration of a majestic mountain in Argentina by another climber. To our knowledge, no research has yet examined whether liberals in the general population apply purity/sanctity arguments to Culture War issues using a Moral Foundations framework. When considering the Keystone XL Pipeline, we predict that liberals will respond with condemnation and recruit primarily sanctity-based arguments to ward off the threat to the pure/sacrosanct environment; conservatives will use primarily fairness-based arguments to ward off the threat to legally acquired corporate-rights. Thus, we predict at least a partial role reversal in the way that liberals and conservatives judge different controversial moral issues.

\section{The Present Studies}

We tested whether liberals and conservatives rely on different moral foundations when making moral judgments about intransigent sociopolitical issues - the legalization of same-sex marriage and approval of the Keystone XL oil pipeline. More specifically, we investigated whether liberals and conservatives alike rely on sanctity-based arguments, depending on the 
context. We predicted that conservatives would perceive the legalization of same-sex marriage as a threat to the sacred value of traditional marriage, and would oppose modifications to marriage law using sanctity-based arguments. As liberals think of marriage in secular terms, we predicted that they would primarily rely on fairness-based arguments. Symmetrically, we predicted that liberals would perceive the Keystone XL Pipeline as a threat to the sacred Earth, and would oppose its development using sanctity-based arguments. As conservatives think of the natural environment as a tool, we predicted that they would primarily rely on fairness-based arguments. To flesh out the views of each side, we relied on new measures and methodologies involving the assessment of both open-ended written (Studies $1 \& 3$ ) and closed-ended scale judgments (Studies $2 \& 4)$.

\section{Study 1}

Using open-ended verbal responses, we tested whether liberals use different moral foundations to justify their differing opinions on same-sex marriage. Because traditional marriage is a conservative institution, we predicted that conservatives would justify their arguments in terms of sanctity and liberals would justify their arguments in terms of fairness.

\section{Method}

Sample. The effect of political ideology on the use of the various foundations ranges from $r=.16$ to $r=.34$ (Graham et al., 2009, p. 1032). To detect effects of $r=.20$ at $80 \%$ statistical power in this and subsequent studies, we required samples of $N=150$. We recruited 146 U.S. respondents on Amazon's Mechanical Turk (Mturk). The sample was 66\% male and 34\% female, 69\% European American, 10\% Black, 5\% Hispanic, 14\% Asian, and 1\% Native American. On average, participants were 31 years old $(S D=10)$, and had 3 years of postsecondary education $(S D=3)$. 
Procedure. Participants offered an opinion about same-sex marriage and a verbal justification of their view, and then reported demographics, which included a measure of political ideology (PI).

Opinions. Below an image of a same-sex couple, the introductions read, "Recently, the legalization of same-sex marriage in some U.S. states, such as California and New Jersey, has received a great deal of media coverage. Some people side with the states that legalized same-sex marriage. They think that its legalization is a good thing. Or they defend same-sex couples' freedom to do what they want. Others disagree with the legalization of same-sex marriage. Whether or not same-sex marriage should have been legalized remains a topic of debate."

The single-item question asked, "What is your opinion? Legalizing same-sex marriage was...". Participants responded on a slider scale anchored at -100 (wrong), 0 (neutral), and 100 (right or $O K$ ). We collected responses on 1 April 2014, at which time approximately half of the U.S. States had legalized same-sex marriage, and the U.S. Supreme Court had not yet rendered a verdict.

Justifications. Participants justified their opinions in an open-ended text box. The prompt read, "Why? Please explain why you feel that way." Responses were required to be > 100 characters. Participants wrote 230 characters $(S D=115)$ on average, which amounted to 43 words $(S D=21)$.

Two judges, blind to participants' PIs and opinions, rated each justification. The instructions for the judges were to "read each justification and make two judgments: How prevalent is fairness? And how prevalent is sanctity?" The instructions defined fairness as "fairness or unfairness/injustice, protecting or violating rights, and equality or inequality." The 
instructions defined sanctity as "purity or impurity, tastefulness or disgust, and sacredness or desecration." Judges independently indicated the prevalence of each theme on a scale anchored at 0 (absent), 1 (implicit), and 2 (explicit). Inter-judge agreement was high for fairness, $r(144)$ $=.83, p<.001$, and for sanctity, $r(144)=.85, p<.001$, so we aggregated their judgments for each foundation.

Political ideology. In this and all subsequent studies, participants reported their political ideology (PI) concerning social issues ${ }^{1}$ on a single item scale, anchored at -4 (strongly liberal), 0 (neutral), and 4 (strongly conservative). The average participant was somewhat liberal, $M=-$ $1.40, S D=2.15$

Analytical strategy. To contrast the thinking of liberals and conservatives, we used standard regression techniques with political ideology as the predictor and opinions or justifications as the outcomes. In addition, we wanted to describe the thinking of each ideology, and to contrast the strength of each side's concerns against one another (within-ideology contrasts). To achieve this, we used regression and recentering techniques (described below). This strategy is superior to trisecting the sample into liberals, moderates, or conservatives in that the recentering approach retains the continuous nature of interval data.

\footnotetext{
${ }^{1}$ Political ideology is inherently multi-dimensional, comprising concerns about social issues (e.g., abortion), economic policy (e.g., progressive taxation), and foreign policy (e.g., doves vs. hawks). However, in the U.S., the multi-dimensional structure began to collapse into a single dimension after the 1960s (Poole \& Rosenthal, 2007). In this study, we also asked participants their ideology on economic issues and foreign policy. Evidencing the single dimensionality of political ideology, the three dimensions were strongly inter-related, $r \mathrm{~s} \geq .58$, and aggregated to $\alpha$ $=.87$. In this and all subsequent studies, we rely on a single measure of social political ideology.
} 
To estimate the views of liberals, we re-centered PI at the middle of the liberal side of ideology $y^{2}$. For example, PI $=-2$ (on the -4 to +4 scale) became PI $=0$. Analogously, we recentered PI on +2 to assess conservatives' functioning. After regressing PI on moral judgments, we took the intercept in the regression equation as the measure of liberals' functioning. In this and subsequent analyses, we use the term "liberals" to specifically mean model-implied participants with PI = -2, and "conservatives" meaning model-implied PI = 2.

\section{Results}

Opinions. Liberals and conservatives reported different opinions about same-sex marriage. Political conservatism predicted opinions about same-sex marriage, $r(144)=-.54, p$ $<.001(\beta=-.56, p<.001$ when controlling for gender). Liberals were strongly in favor, $M=75$, $95 \% \mathrm{CI}=[66,84], p<.001$. Conservatives were neutral, $M=14,95 \% \mathrm{CI}=[-2,30], p=.08$

Justifications. A conservative participant condemned same-sex marriage as "an abomination to god," calling it "just as disgusting and immoral as most crimes committed by criminals." This sanctity/disgust frame is different from a typical liberal defense: "I believe it's discriminatory against gays to deny them equal protection under the law." This anecdotal difference generalized. Political conservatism predicted the use of sanctity, $r(144)=.47, p$ $<.001(\beta=.48, p<.001$ when controlling for gender), and fairness, $r(144)=-.43, p<.001(\beta=$ $-.43, p<.001$ when controlling for gender) see Figure 1).

To test whether liberals used more fairness than sanctity, we accommodated the withinsubject nature of the data by calculating difference scores for each participant. We then regressed re-centered PI on difference scores and interpreted the constant as an inter-foundation contrast.

\footnotetext{
${ }^{2}$ We did not re-center at the $M \pm 1 S D$ because the individual sample $M$ s are of little theoretical interest. Rather, the scale midpoint, PI $=0$, represents the construct of theoretical and practical importance — political neutrality (see Motyl, Iyer, Oishi, Trawalter, \& Nosek, 2014).
} 
Liberals' justifications emphasized fairness more than sanctity, $B_{\text {difference }}=1.28, S E=0.83, p$

$<.001$. Conservatives' justifications were equal parts fairness and sanctity, $B_{\text {difference }}=0.16, S E=$ $0.15, p=.31$

Mediation. We tested whether fairness and sanctity arguments help explain why liberals and conservatives disagree about same-sex marriage. Using Preacher and Hayes' (2008) bootstrapping procedure, with PI as the predictor, opinions as the outcome, and the two foundations as mediators, we found that both fairness and sanctity helped explain the disagreement (see Table 1).

\section{Discussion}

Liberals support same-sex marriage in the name of fairness; conservatives oppose samesex marriage as a threat to the sacrosanct institution of traditional marriage, however fairness and sanctity were equally prevalent in the arguments of conservatives. This could be a feature of the rather blunt means of determining the prevalence of each foundation. Or, conservatives' concerns for promoting fairness may oppose their concern for preventing desecration. The equal presence of fairness and sacredness does not imply equal valence. Study 2 addressed this issue by assessing how liberals and conservatives think about same-sex marriage more precisely.

\section{Study 2}

Study 2 relied on objective scales to test whether conservatives rely more on sanctity, and liberals rely more on fairness when justifying their opinions about same-sex marriage. In particular, the scales assessed people's perceptions of the effects that same-sex marriage will have on society, and how relevant each effect is to their moral opinion. We assessed closely related moral foundations (viz. care \& authority) to more fully flesh out each side's opinion. Our 
main prediction was that fairness and sanctity would be the primary distinguishing considerations between the moral judgments of liberals and conservatives.

\section{Method}

Sample. Participants were 152 U.S. respondents on Mturk. The sample was $50 \%$ male and 50\% female, $81 \%$ European American, 7\% Black, 4\% Hispanic, and 7\% Asian. On average, participants were 39 years old $(S D=14)$, had 4 years of post-secondary education $(S D=3)$, and had a median household income between $\$ 40,000$ and $\$ 50,000$.

Procedure. The survey was similar to that in Study 1, except we replaced the open-ended justification with closed-ended scales measuring four moral foundations.

Opinions. The measure was identical to that in Study 1.

Justifications. We used Frimer et al.'s (2015) adapted version of the Moral Foundations Questionnaire (MFQ; Graham et al., 2009) which disentangles the perceived moral effects of a particular societal change (e.g., legalizing same-sex marriage) and the perceived relevance of each effect to their moral judgments about this issue. These scales allow us to form a specific picture of how the camps think about issues.

Effects. Table 2 contains the items. The scale asked participants whether same-sex marriage would promote, undermine, or have no influence over foundations of care, fairness, authority, and sanctity. We did not include items concerning loyalty to not overtax participants and because past research (Frimer, Biesanz, Walker, \& MacKinlay, 2013; Frimer et al. 2015) found loyalty to be the least relevant foundation on issues concerning the environment and leadership. The items appeared in random order between subjects ${ }^{3}$.

\footnotetext{
${ }^{3}$ We excluded one fairness item (“...cheat or uphold acceptable standards of behavior”) because it did not correlate with the other fairness items, and thus undermined reliability.
} 
Relevance. Following each effect judgment, and on the same web page, participants indicated how relevant each effect is to their opinion on a scale anchored at 0 (not at all), 50 (somewhat), and 100 (extremely). The question asked, "to what degree is this relevant to your opinion about whether legalizing same-sex marriage was right or wrong?" We aggregated their judgments for each foundation, $\alpha \mathrm{s}=.71$ to .86 .

Political ideology. The average participant was slightly liberal, $M=-0.9, S D=2.6$.

\section{Results}

Disagreements. Liberals and conservatives again expressed different opinions about legalizing same-sex marriage. Political conservatism negatively predicted approval, $r(150)=$ $-.72, p<.001(\beta=-.72, p<.001$ when controlling for gender). Liberals claimed that legalization of same-sex marriage would have more positive effects on society in terms all four foundations (see Table 2). Compared to liberals, conservatives thought that care and fairness were less relevant and authority and sanctity were more relevant considerations (see Table 3).

Conservative opposition. Conservatives reported negative views toward legalizing same-sex marriage, $M=-40, S E=7, p<.001,95 \% \mathrm{CI}=[-54,-26]$.

Effects. At the item level, the primary conservative arguments were that same-sex marriage would dishonor tradition $\left(M_{\text {effect }}=-56\right)$, undermine standards of purity $(-48)$, desecrate marriage (-44), and be disgusting (-40). At the foundation level, they claimed that legalization would undermine authority and sanctity (but would have no net effect on care or fairness; see Figure 2). Their primary justification was sanctity-based, $M_{\text {sanctity-authority }}=-8, S E=4, p=.02$, $95 \% \mathrm{CI}=[-1,-16]$.

Relevance. At the item level, the most relevant items concerned the desecration of marriage (78), tradition (74), standards of purity (73), and respect (65). In descending order, the 
most relevant foundations for conservatives were sanctity (62), authority (59), fairness (49), and care (42; all of which differed from one another at $p<.03$, with the exception of authority vs. sanctity, $p=.18)$.

Liberal support. Liberals reported positive views toward legalizing same-sex marriage, $M=55, S E=5, p<.001,95 \% \mathrm{CI}=[45,66]$.

Effects. At the item level, the primary liberal justifications were that same-sex marriage would amount to the fair treatment of others $\left(M_{\mathrm{effect}}=64\right)$, protect rights $(-64)$, be compassionate (-61), and relieve emotional suffering (-53). At the foundation level, they claimed that legalizing same-sex marriage would be fair, caring, respectful, and sanctifying (see Figure 2). Fairness was their primary justification, $M_{\text {fairness-care }}=14, S E=3, p<.001,95 \% \mathrm{CI}=[7,20]$.

Relevance. At the item level, the most relevant items concerned the fair treatment of others (89), protecting rights (89), compassion (70), and relieving suffering (64). In descending order, the most relevant foundations for liberals were fairness (76), care (57), authority (46), and sanctity (43; all of which differed from one another at $p<.001$, with the exception of authority vs. sanctity, $p=.12$ )

Mediation. We tested whether care, fairness, authority and sanctity arguments help explain why liberals and conservatives disagree about same-sex marriage. Using Preacher and Hayes' (2008) bootstrapping procedure, with PI as the predictor, opinions as the outcome, and the four foundations as mediators, we found that only fairness and sanctity helped explain the disagreement (see Table 4).

\section{Discussion}

Liberals again defended same-sex marriage primarily in terms of fairness, whereas conservatives opposed same-sex marriage primarily in terms of sanctity. A valenced scale 
provided evidence that sanctity was the primary grounds for conservative opposition. Taken together, Studies 1 and 2 found that liberals' fairness arguments talk past conservatives' sanctity arguments regarding same-sex marriage. Relying on MFT (e.g., Graham et al., 2009), these results help explain the difficulty underlying the disagreements between liberals and conservatives on the controversial issue of same-sex marriage. Specifically, conservatives view the issue primarily in terms of sanctity and authority, whereas liberals view the issue primarily in terms of fairness and compassion. When conflicted parties disagree on the basic premises of the issue in question, the conflict between them tends to be more exaggerated and intractable (Waytz, Young, \& Ginges, 2014).

Studies 1 and 2 also serve to validate a new and then revised measure of moral justification and demonstrate that liberals and conservatives use different moral foundations when justifying their attitudes toward same-sex marriage. As predicted, liberals' justifications relied more on fairness and compassion and conservatives' justifications relied more on authority and sanctity. This finding is consistent with the predictions of political differences made by MFT (Graham et al., 2013). Although not yet studied, there may be issues where liberals' justify their attitudes using sanctity-based arguments and where conservatives' justify their attitudes using fairness-based arguments. We test this possibility in Studies 3 and 4.

\section{Study 3}

Some scholars suggest that while conservatives sanctify sexuality and sexual behavior, liberals may sanctify the environment (e.g., Haidt, 2010; Rottman, 2014). In Study 3, we sought to test whether liberals and conservatives again rely on different moral foundations when debating a different controversial issue - the Keystone XL oil pipeline. 
If approved, the pipeline would transport crude oil products from the Canadian oil sands to refineries in the U.S. Environmentalists have raised concerns about potential oil spills in the ecologically sensitive Ogallala Aquifer (Nebraska) and its contribution to climate change.

Insofar as the environment may be sacrosanct to liberals, we predicted that liberals would use sanctity-based arguments more than conservatives. As conservatives think of nature more pragmatically, we predicted that they would rely on more fairness-based arguments. That is, we predicted that liberals and conservatives would, in important ways, trade moral foundations when changing the topic from same-sex marriage to the oil pipeline.

\section{Method}

Sample. We recruited 200 U.S. respondents on Mturk, of which 47 reported feeling "not at all knowledgeable" about the Keystone Pipeline on a post hoc screening question. We retained the $N=153$ who claimed to have some knowledge of the pipeline. The sample was $78 \%$ male and 22\% female, $88 \%$ European American, 3\% Black, 1\% Hispanic, 5\% Asian, and 3\% Native American. On average, participants were 37 years old $(S D=14)$, and had 3.9 years of post-secondary education $(S D=2.7)$.

Procedure. Participants completed an online survey on 12 May 2014, at which time the pipeline application was pending a final decision from U.S. authorities. The survey was similar to that in Study 1, except the present survey concerned the Keystone XL Pipeline.

Opinions. Below an image of heavy machinery lowering a pipe into excavated earth, the introductions read,

"Recently, the proposed Keystone XL Pipeline from Canada to the U.S. has received a great deal of media coverage. Some people side with approving the pipeline. They think that it's a good thing. Or they defend corporations' right to 
do business. Others side with not approving the pipeline. Whether or not the pipeline should be approved remains a topic of debate."

The single-item question asked, "What is your opinion? Approving the Keystone Pipeline would be...". Participants responded on a slide scale anchored at -100 (wrong), 0 (neutral), and 100 (right or $O K)$.

Justifications. Participants justified their opinions in an open-ended text box identical to that in Study 1. Participants wrote 199 characters on average $(S D=102)$, which amounted to 37 words $(S D=18)$.

Judges. The same two judges as in Study 1 used the same procedure. They agreed on the prevalence of both fairness, $r(151)=.87, p<.001$, and sanctity, $r(151)=.78, p<.001$, so we aggregated their judgments.

Political ideology. The average participant was slightly liberal, $M=-0.33, S D=2.31$.

\section{Results}

Opinions. Political conservatism predicted opinions about the pipeline, $r(151)=.47, p$ $<.001(\beta=.46, p<.001$ when controlling for gender). Conservatives were in favor, $M=53$, $95 \% \mathrm{CI}=[35,71], t=5.95, p<.001$. Liberals were neutral, $M=-4,95 \% \mathrm{CI}=[-15,6], t=-$ $0.82, p=.41$.

Justifications. Most of the justifications concerned pragmatic changes (e.g., creating jobs, strengthening the economy, gaining independence from Middle Eastern countries, and altering the environment) without specifying the moral significance of these changes. For this reason, morality (both explicit and implicit) was less prevalent here than in the debate over samesex marriage. However, differences between liberals and conservatives still emerged. 
A liberal participant condemned the pipeline on the grounds that it would "spoil the pristine condition of nature." This purity/sanctity frame "talks past" the fairness frame of the conservative defense: "A business has the right to move forward with projects that are approved by officials." More generally, political conservatism predicted the use of both sanctity, $r(151)=$ $-.25, p=.002(\beta=-.25, p=.002$ when controlling for gender), and fairness, $r(151)=.13, p=.05$ $(\beta=.12, p=.15$ when controlling for gender), in the justification of opinion (see Figure 3 ).

Mediation. We tested whether fairness and sanctity arguments help explain why liberals and conservatives disagree about the Keystone XL Pipeline. Using an analysis analogous to that in Study 1, we found that only sanctity helped explain the disagreement, with the direction of the effect reversed from that found with same-sex marriage (see Table 1).

Data-driven analysis. Having found that sanctity and fairness were relatively infrequent in justifications for opinion on the pipeline, we decided to conduct a data-driven analysis of the same justifications to look for possible theoretical blind spots. We reviewed participants' justifications and identified common themes. Twelve themes emerged (see Table 5). Next, two coders rated the presence or absence of each theme in each justification. Justifications often mentioned more than one theme so we instructed the coders to rate each theme independently. On average, justifications had 2.1 themes $(S D=0.9)$. We then assessed the reliability of the coding and found that all 12 had high levels agreement $(\geq 89 \%)$ but three had poor $\kappa s$ (.14-.32), perhaps due to their low frequency. The remaining nine themes had consistently high $\kappa s(.71-.91)$; we retained only the nine reliable themes in further analyses.

Our analyses found that liberals and conservatives differed in how often they mentioned four themes (see Table 5). Conservatives more often cited (a) the importance of bringing energy to consumers efficiently and safely, and (b) fostering independence from the Middle East. 
Meanwhile, liberals were more inclined to cite (a) environmental damage and (b) that the pipeline would foster a reliance on oil. We entered these four themes into a mediation model (ideology $\rightarrow$ theme $\rightarrow$ opinion, with all four themes entered as simultaneous mediators) and found that all four themes helped explain why liberals and conservatives disagreed about the pipeline.

\section{Discussion}

The moral arguments of liberals versus conservatives on same-sex marriage versus the Keystone Pipeline exhibit some aspects of ideological symmetry. Specifically, these findings are among the first to suggest that liberals can, in some situations, harbor more concern for the sacrosanct than do conservatives.

Fairness and sanctity, as explicit themes, were relatively infrequent. A data-driven analysis revealed that ideological differences in opinion about the pipeline boil down to conservatives concern about bringing energy to consumers and fostering independence from foreign oil and liberals' concerns about environmental damage and encouraging reliance on oil in general. While these themes are not explicitly moral in nature, they may reflect implied moral concerns, implicitly. For example, conservatives may be concerned about bringing oil to market as energy helps sustain the economy. And, they may see the economy as a level playing field that provides a fair and equal opportunity to earn an income and support a family. Similarly, liberals may voice concern about environmental damage because of the life-sustaining function of healthy eco-systems and/or because they think of the earth as pure and sacred. In the absence of follow-up prompting (e.g., in an interview), such ambiguities are endemic to open-ended responses. To probe the specific thought processes that liberals and conservatives bring to the Keystone pipeline, we used closed-ended questions in Study 4. 


\section{Study 4}

Study 4 used the objective measures as in Study 2 to more fully describe opinions about the Keystone XL Pipeline. We predicted that liberals would use sanctity-based arguments to oppose the pipeline, and conservatives would use fairness-based arguments to support it.

\section{Method}

Sample. We recruited 290 U.S. respondents on Mturk, and retained the 213 who claimed to have some knowledge of the pipeline. The sample was $76 \%$ male and $24 \%$ female, $78 \%$ European American, 9\% Black, 5\% Hispanic, 6\% Asian, and 1\% Native American. On average, participants were 32 years old $(S D=9)$, had 3.7 years of post-secondary education $(S D=2.6)$, and had a median household income between $\$ 30,000$ and $\$ 40,000$.

Procedure. Participants completed an online survey on 19 March 2014, at which time the pipeline application was pending a final decision from U.S. authorities. The study was similar to that in Study 2 except the issue was the Keystone Pipeline.

Opinion. This measure was identical to that in Study 3.

Justification. The scale asked participants about the effects of approving the pipeline in terms of four foundations ( $\alpha \mathrm{s}=.70$ to .84 ), and the relevance of each foundation to their moral judgment ( $\alpha$ s $=.69$ to .72$)$. We used the same scale as in Study 2 with three necessary, minor alterations: we changed the original prompt to read, "Would approving the pipeline...", the final scale item to read "...desecrate or sanctify nature," and the relevance question finished "...about whether approving the pipeline is right or wrong."

Political Ideology. The sample was somewhat liberal, $M=-1.5, S D=2.3$. 


\section{Results}

Disagreements. Political conservatism predicted overall opinions toward the pipeline, $r(211)=.51, p<.001(\beta=.50, p<.001$ when controlling for gender $)$. Compared to liberals, conservatives claimed that the pipeline would have more positive societal effects in terms of each of the four foundations (see Table 2). And, once again, compared to liberals, conservatives reported that care and fairness were less relevant and authority more relevant considerations to their opinions (see Table 3). Critically, however, liberals now thought that sanctity was more relevant to their moral opinion than conservatives did.

Liberal opposition. Liberals reported negative views toward the pipeline, $M=-8, S E=$ $4, p=.03,95 \% C I=[-1,-16]$.

Effects. At the item level, the primary liberal justifications were that the pipeline would desecrate nature (-50), harm the weak or vulnerable (-28), undermine standards of purity (-18), and be disgusting (-13). At the foundation level, they claimed that approving the pipeline would undermine care, fairness, and sanctity (but not authority; see Figure 4). Their strongest justification was desecration, $M_{\text {sanctity-care }}=-11, S E=2, p<.001,95 \% C I=[-7,-14]$.

Relevance. At the item level, the most relevant items concerned the desecration of nature $\left(M_{\text {effect }}=71\right)$, protecting the weak and vulnerable (63), protecting rights (54), and fair treatment of others (51). In descending order, the most relevant foundations for liberals were fairness (53), care (52), sanctity (48), and authority (43; all of which differed from one another at $p<.03$ with the exception of care vs. fairness, $p=.21$ ).

Conservative support. Conservatives reported positive views toward the pipeline, $M=$ 49, $S E=7, p<.001,95 \% C I=[36,63]$. 
Effects. At the item level, the primary conservative justifications were that the pipeline would promote order $\left(M_{\text {effect }}=37\right)$, the fair treatment of others $(30)$, protect rights $(29)$, and relieve emotional suffering (23). At the foundation level, they claimed that approving the pipeline would promote foundations of care, fairness, and authority, but would have no effect on sanctity (see Figure 4). Their strongest justification was fairness, $M_{\text {fairness-authority }}=8, S E=4, p$ $=.02,95 \% C I=[1,16]$.

Relevance. At the item level, the most relevant items concerned the fair treatment of others (52), order (52), purity (43), and suffering (42). In descending order, the most relevant foundations for conservatives were fairness (44), authority (43), care (39), and sanctity (36; none of which differed from one another with the exception of sanctity vs. fairness, $p=.04$ ).

Mediation. We tested whether the perceived effects in terms of caring, fairness, authority, and sanctity help explain why liberals and conservatives disagree about the Keystone XL Pipeline. Using an analysis analogous to that in Study 2, we found that all four foundations helped explain the disagreement, with the direction of the effects reversed from those found with same-sex marriage (see Table 4).

\section{Discussion}

Study 4 found that, in important ways, liberals and conservatives can trade moral arguments when changing the topic from same-sex marriage to the oil pipeline. Liberals' primary complaint about the pipeline was based on sanctity concerns. And liberals claimed that sanctity was a more relevant consideration to their opinion than did conservatives. Liberals also cited the effects and relevance of harm and unfairness, suggesting that liberals may moralize the pipeline more so than conservatives. For conservatives, the primary moral concern was fairness. And follow-up analyses found that conservatives cited economic and foreign policy implications in 
their support for the pipeline. These ostensibly non-moral factors may, however, connote moral undertones. For example, conservatives may conceive of the economy as a vehicle for equal opportunity, a fairness consideration. However, future research is needed to test whether conservatives think of the economy as delivery system for moral ends. The results from Studies 3 and 4 are the first to our knowledge to show that liberals can base their moral opinions on sanctity more than conservatives do when voicing opinions about Culture War issues.

\section{General Discussion}

Liberals and conservatives think about contentious issues using different moral languages. Conservatives denounced the legalization of same-sex marriage as a desecration, whereas liberals supported same-sex marriage as a matter of fairness. These differences were evident in both open-ended justifications (Study 1) and in close-ended scales (Study 2). Study 3 demonstrated that the same sorts of differences emerge on environmental issues, albeit with liberals and conservatives, in some ways, reversing opinions and arguments. Conservatives supported the Keystone XL Pipeline primarily on grounds of fairness (e.g., a corporation's right to do business), whereas liberals denounced the pipeline, primarily citing that it violates the sanctity of nature (as well as causing harm and unfairness; Studies 3 and 4).

These results suggest that these intransigent ideological issues may, in part, be a product of one side thinking in terms of fairness while the other perceives a threat to the sacrosanct. If so, the prospects for compromise on environmental issues and alterations to the traditional definition of marriage are bleak. A major impediment is that the side that sacralizes sees compromise and trade-offs as unacceptable. Perhaps reframing these issues in non-sacralized terms could open opportunities for open-minded discussion.

\section{Morality is Heterogeneous}


Fairness-based and sanctity-based arguments mix as poorly as oil and water because morality may be functionally heterogeneous. Moral Foundations Theory claims the existence of several distinct moral foundations: harm, fairness, loyalty, authority, and sanctity (Graham et al., 2009; and maybe liberty, Haidt, 2012; but see Rai \& Fiske, 2011, and Shweder, 1999 for other accounts arguing multiple, distinct moral domains). When an act is wrong because it is unfair (e.g., showing favoritism to heterosexual couples), quantitative adjustments provide a remedy (e.g., change the marriage law to include same-sex couples). In contrast, when an act is wrong because a person sees it as disgusting (e.g., homosexuality), the remedy is total proscription. The logic of revision associated with fairness does not mesh with the absolute thinking associated with sanctity. Future research could investigate whether a mismatching of foundational arguments can explain other ideological debates, such as over gun control, abortion, and affirmative action.

\section{Policy Implications}

This research could inform efforts to build popular support for policy initiatives on morally charged issues. The key insight from this research is that understanding the moral experiences of liberals and conservatives can be a critical first step in understanding why opinions diverge. Without this insight, media campaigns may fail to take the perspective of the opposition and effectively talk past the opposition's point of view.

Future research should investigate whether and which type of media campaigns can shift which moral foundation liberals or conservatives bring to an issue, and whether this change can alter their respective levels of support for public policy initiatives. Some previous research suggests that the combination of language and images can cause conservatives to support environmental policy (Feinberg \&Willer, 2013). Further research is needed to investigate why 
specifically media campaigns like these are effective, whether they can shift the perspectives and opinions of liberals too, and the conditions under which they may backfire.

\section{Ideological Symmetry Across the Ideological Divide}

Moral foundations may have a dispositional component, embodied as stable individual differences. Compared to conservatives, liberals tend to rely more on harm and fairness, and less on loyalty, authority, and sanctity (e.g., Graham et al., 2011). However, liberals and conservatives may be more alike than previously thought. The results of the present studies suggest that people vary in their use of these foundations across contexts. For example, we demonstrated a near-complete role-reversal in the use of fairness vis-à-vis sanctity-based justifications of moral opinions.

Ideological symmetry was manifest in reversing effects when changing the topic from same-sex marriage to the oil pipeline. First, open-ended responses yielded near perfect symmetry. When judging same-sex marriage legislation, conservatism positively predicted the use of sanctity-based arguments $(r=+.47)$ and fairness-based arguments but in the opposite direction $(r=-.43)$. Symmetrically, on the Keystone pipeline, conservatism negatively predicted the use of sanctity-based arguments $(r=-.25)$ and positively predicted the use of fairness-based arguments $(r=+.13)$. The larger effects on same-sex marriage than the pipeline may be because both sides used clearer moral language when talking about marriage, and because liberals and conservative may also think about the pipeline in economic terms; this attenuated pattern, with same sex marriage effects being stronger than oil pipeline effects, appears in all subsequent ideological symmetry analyses. Past research demonstrates that political attitudes that are discussed more in culture and in media often become moralized over time (Clifford, Jerit, Rainey, \& Motyl, 2015). Therefore, the larger effects observed for same-sex marriage may be 
due to the greater press coverage it has received in recent decades relative to the more recent coverage of the Keystone XL pipeline.

Second, the primary perceived effects of same-sex marriage and the pipeline also exhibited mirror symmetry. On same-sex marriage, conservatives' primary concern was desecration ( -44 on a -100 to +100 scale); for liberals, the primary effect was fairness $(+64)$; in contrast, on the pipeline, conservatives primarily were concerned about fairness $(+30)$ and liberals' primary grievance was desecration (-27). Third, compared to liberals, conservatism predicted the perceived relevance of sanctity to the issue of same-sex marriage $(r=+.36)$ and the pipeline $(r=-.14)$. And fourth, in mediation analyses, fairness almost always, and sanctity always, helped explain the disagreements, with the direction of the mediation paths flipping reliably. Sanctity explained more of the disagreement on same-sex marriage $(B=-7.1,-10.7)$ than on the pipeline $(\mathrm{B}=2.2,2.3)$.

A limitation of the present research is that we found two noteworthy exceptions to the ideological symmetry hypothesis, both on the topic of perceived relevance. First, liberals claimed that fairness was a more relevant concern on both issues. And second, conservatives reported that sanctity was the most relevant foundation when judging same-sex marriage, and fairness was most relevant to the pipeline. Liberals claimed that fairness was most relevant to same-sex marriage, but did not claim that sanctity was most relevant to the pipeline (despite desecration being their most pronounced perceived effect.) This may be because liberals are less willing to admit that feeling disgusted is grounds for moral condemnation or because liberals may also perceive harm in environmental damage. For example, some liberals may find gay sex to be disgusting, but feel reluctant to say that feeling disgusted is grounds for judging others or limiting their rights. A second limitation of the present research was the singular reliance on 
self-report, explicit methods. People may be unaware of what factors influence their moral judgments (Wilson \& Dunn, 2004). Future research should investigate the ideological symmetry hypothesis issue using behavioral and implicit methods for assessing attitudes. A third limitation is the correlational nature of the link between justifications and opinions. A foundation being the most prevalent does not imply that it was causally responsible for the opinion. Future research should use experimental methods to test whether (and which) foundations are causally responsible for opinions on these controversial topics.

Another limitation of the present studies was the samples that tended to have more males than females. This was especially the case in Studies 3-4, which were on the topic of the Keystone XL Pipeline. Perhaps males felt more knowledgeable or more interested in the topic and therefore chose to remain in the survey. More generally, the sole reliance on Mechanical Turk to recruit participants was a limitation of the present studies. Mechanical Turk samples are not necessarily representative of the population (Bohannon, 2016).

Both liberals and conservatives may have the proclivity to treat certain entities as a means to an end, as open to "trade-offs" for the sake of fairness (Tetlock, 2003). And both sides may also treat certain entities as ends in their own right, as sacrosanct and inviolable. While we did demonstrate some aspects of ideological symmetry between issues of same-sex marriage and the environment, we did not establish complete symmetry between the ideologies. This leaves open the possibility that conservatives sacralize more than liberals do (Graham et al. 2009, 2011).

\section{The Origin of Sacred Values}

Why might conservatives sacralize traditional marriage and liberals sacralize the environment? More generally, do sacralized objects or practices match the ideology of a group 
in some systematic way, or are sacralized objects or practices arbitrary conventions that only gain meaning through decree, contagion, and ritual?

Clearly, some element of arbitrariness is at play in the elevation of the mundane to the sacrosanct. To illustrate, the relationship between Christianity and the cross is a product of an arbitrary convention - the means by which the Roman Empire performed executions 2000 years ago. Had Jesus lived in another era, Christians may have sacralized a noose, stone, cauldron, syringe, or guillotine. Arbitrary decree was also involved in the sacralisation of marriage. Prior to the year 1563, the church treated marriage as secular; only at the Council of Trent did the Catholic Church make marriage sacrosanct by decree. Similarly, the Left may have begun to sacralize the environment after the Industrial Revolution and the writings of Henry David Thoreau, John Muir, and Rachel Carson (Griswold, 2012).

Arbitrariness and historical artefact notwithstanding, we suggest that sacralized objects/practices tend to conceptually match the group's existential meaning. A defining feature of conservative ideology is social hierarchy - the notion that some people should have and deserve power and privilege over others (Pratto, Sidanius, Stallworth, \& Malle, 1994). Perhaps the Right is most likely to sacralize practices or objects that represent the maintenance of social hierarchy (e.g., traditional marriage). In contrast, the Left idealizes social equality - the notion that all people should have equal power and privilege. Perhaps the Left is most likely to sacralize practices or objects that represent the levelling of power and promotion of social equality (e.g., the environment). In sum, we suggest that both arbitrariness and order are both at play in the adoption of sacred objects/practices. However, future research is needed to investigate this question. 
Treating a mundane object as infinite and unalterable is plainly irrational, and counterproductive for a self-interested maximizing being. However, the social nature of humans may make sacralization worth the effort. The irrational and costly nature of sacralization serves a social function - it communicates to others one's allegiance to the group. Group members then know that the adherent is worthy of help and loyalty; the end result is a strong, tightly bound group. Arbitrarily sacralizing any object (e.g., a beer can) or practice (e.g., hand washing) could serve this function.

\section{Moralistic Thinking on the Left and Right}

This study joins a growing literature that suggests that liberals and conservatives are more alike in their moral functioning than previously thought. Like conservatives, liberals discriminate against outgroups (Wetherell, Brandt, \& Reyna, 2013) and demand that other people obey their group's authorities (Frimer, Gaucher, \& Schaefer, 2014). Like conservatives, liberals idolize leaders like Gandhi, Mother Teresa, and Martin Luther King, Jr. (Frimer et al., 2013). Like conservatives, liberals attribute responsibility for misdeeds to the perpetrator (rather than extenuating circumstances) when the perpetrator is from an outgroup (Morgan, Mullen, \& Skitka, 2010). Like conservatives, liberals have morals concerning the self, close others, and the collective group (Janoff-Bulman \& Carnes, 2013). Both liberals and conservative are similarly motivated to remain ignorant of one anothers' views and resist attempting to take the perspective of the other side (Chopik \& Motyl, in press; Frimer, Skitka, \& Motyl, 2016). And, liberals and conservatives alike tend to view each other in similarly negative ways and as subhuman (Crawford, Modri, \& Motyl, 2013). 


\section{Conclusion}

Some polemic debates, such as those on the topics of same-sex marriage and environmental damage, may be a result of liberals and conservatives talking past one another, with one side making fairness-based arguments, and the other side making sanctity-based arguments. Liberals and conservatives alternate between seeing certain issues as a matter of fairness, and others as sacrosanct. These findings lend insight into the moral experience of one's opponents. If liberals want to know what it feels like to be a conservative opposing same-sex marriage, they only need consider how they themselves feel about the environment.

\section{Funding}

This research was prepared with support from a Social Sciences and Humanities Research Council of Canada grant to Jeremy Frimer [435-2013-0589]. 


\section{Conflict of Interest}

The author(s) declared no potential conflicts of interest with respect to the research, authorship, and/or publication of this article.

\section{Author Bios}

JEREMY A. FRIMER is Assistant Professor of Psychology at the University of Winnipeg. He received his $\mathrm{PhD}$, MA, and BASc from the University of British Columbia. His research interests include ideology, morality, and leadership.

MATT MOTYL is Assistant Professor of Social Psychology and Political Science at the University of Illinois at Chicago. His research examines moral and political cleavages in society, and what can be done to promote more civil dialogue on moral and political matters.

CAITLIN E. TELL completed her BA with honors in Psychology at the University of Winnipeg and now works in the public sector. 


\section{References}

Atran, S., \& Norenzayan, A. (2004). Religion's evolutionary landscape: Counterintuition, commitment, compassion, communion. Behavioral and Brain Sciences, 27, 713-770. doi:10.1017/S0140525X04000172

Bohannon, J. (2016). Mechanical Turk upends social sciences. Science, 352, 1263-1264. doi: $10.1126 /$ science. 352.6291 .1263

Chopik, W. J., \& Motyl, M. (in press). Ideological fit enhances interpersonal orientations. Social Psychological and Personality Science.

Clifford, S., Jerit, J., Rainey, C., \& Motyl, M. (2015). Moral concerns and policy attitudes: Investigating the influence of elite rhetoric. Political Communication, 32(2), 229-248.

Crawford, J. T., Modri, S. A., \& Motyl, M. (2013). Bleeding-heart liberals and hard-hearted conservatives: Subtle political dehumanization through differential attributions of human nature and human uniqueness traits. Journal of Social and Political Psychology, 1, 86-104.

Durkheim, E. (1995/1915). The Elementary Forms of Religious Life. Trans. K. E. Fields. New York: Free Press.

Feinberg, M., \& Willer, R. (2013). The moral roots of environmental attitudes. Psychological Science, 24, 56-62. doi:10.1177/0956797612449177

Franks, A. S., \& Scherr, K. C. (2015). Using moral foundations to predict voting behavior: Regression models from the 2012 U.S. Presidential election. Analyses of Social Issues and Public Policy (ASAP), 15, 213-232. doi:10.1111/asap.12074

Frimer, J. A., Biesanz, J. C., Walker, L. J., \& MacKinlay, C. W. (2013). Liberals and conservatives rely on common moral foundations when making moral judgments about influential people. Journal of Personality and Social Psychology, 104, 1040-1059. doi:10.1037/a0032277 
Frimer, J. A., Gaucher, D. \& Schaefer, N. K. (2014). Political conservatives' affinity for obedience to authority is loyal, not blind. Personality and Social Psychology Bulletin, 40, 1205-1214. doi: $10.1177 / 0146167214538672$

Frimer, J. A., Skitka, L. J., \& Motyl, M. (2016). Liberals and conservatives are similarly motivated to remain ignorant of one another's opinions. manuscript under review.

Frimer, J. A., Tell, C. E. \& Haidt, J. (2015). Liberals condemn sacrilege too: The harmless desecration of Cerro Torre. Social Psychological and Personality Science. doi: $10.1177 / 1948550615597974$

Graham, J., Haidt, J., Koleva, S., Motyl, M., Iyer, R., Wojcik, S., \& Ditto, P. H. (2013). Moral Foundations Theory: The pragmatic validity of moral pluralism. Advances in Experimental Social Psychology, 47, 55-130. doi:10.1016/B978-0-12-407236-7.00002-4

Graham, J., Haidt, J., \& Nosek, B. A. (2009). Liberals and conservatives rely on different sets of moral foundations. Journal of Personality and Social Psychology, 96, 1029-1046. doi:10.1037/a0015141

Graham, J., Nosek, B. A., Haidt, J., Iyer, R., Koleva, S., \& Ditto, P. H. (2011). Mapping the moral domain. Journal of Personality and Social Psychology, 101, 366-385. doi:10.1037/a0021847

Griswold, E. (2012, September 21). How "Silent Spring” ignited the environmental movement. The New York Times

Haidt, J. (2007). The new synthesis in moral psychology. Science, 316, 998-1002. doi:10.1126/science.1137651

Haidt, J. (2010). In search of liberal purity. Blog post retrieved on October 24, 2014, from http://www.yourmorals.org/blog/2010/02/in-search-of-liberal-purity/ 
Haidt, J. (2012). The righteous mind: Why good people are divided by politics and religion. New York, NY: Random House, Inc.

Janoff-Bulman, R., \& Carnes, N. C. (2013). Surveying the moral landscape: Moral motives and group-based moralities. Personality and Social Psychology Review, 17, 219-236. doi: $10.1177 / 1088868313480274$.

Johnson, K. M., Iyer, R., Wojcik, S. P., Vaisey, S., Miles, A., Chu, V., \& Graham, J. (2014). Ideology-specific patterns of moral indifference predict intentions not to vote. Analyses of Social Issues and Public Policy (ASAP), 14, 61-77. doi:10.1111/asap.12039

Koleva, S. P., Graham, J., Iyer, R., Ditto, P. H., \& Haidt, J. (2012). Tracing the threads: How five moral concerns (especially Purity) help explain culture war attitudes. Journal of Research in Personality, 46, 184-194. doi:10.1016/j.jrp.2012.01.006

Morgan, G. S., Mullen, E., \& Skitka, L. J. (2010). When values and attributions collide: Liberals' and conservatives' values motivate attributions for alleged misdeeds. Personality and Social Psychology Bulletin, 36, 1241-1254. doi:10.1177/0146167210380605

Motyl, M., Iyer, R., Oishi, S., Trawalter, S., \& Nosek, B. A. (2014). How ideological migration geographically segregates groups. Journal of Experimental Social Psychology, 51, 1-14.

Poole, K. T. \& Rosenthal, H. L. (2007). Ideology and Congress. New Brunswick, NJ: Transaction.

Pratto, F., Sidanius, J., Stallworth, L. M., \& Malle, B. F. (1994). Social dominance orientation: A personality variable predicting social and political attitudes. Journal of Personality and Social Psychology, 67, 741-763. 
Preacher, K. J., \& Hayes, A. F. (2008). Asymptotic and resampling strategies for assessing and comparing indirect effects in multiple mediator models. Behavior Research Methods, 40, 879-891. doi:10.3758/BRM.40.3.879

Rai, T. S., \& Fiske, A. P. (2011). Moral psychology is relationship regulation: moral motives for unity, hierarchy, equality, and proportionality. Psychological Review, 118, 57.

Rawls, J. (1971). A theory of justice. Cambridge, MA: Harvard University.

Rottman, J. (2014). Breaking down biocentrism: two distinct forms of moral concern for nature. Frontiers in Psychology, 5. doi:10.3389/fpsyg.2014.00905

Sachdeva, S., \& Medin, D. (2009). Group identity salience in sacred value based cultural conflict: An examination of the Hindu-Muslim identities in the Kashmir and Babri Mosque issues. Proceedings of the 31th Annual Conference of the Cognitive Science Society, 3111-3114. Retrieved from http://csjarchive.cogsci.rpi.edu/Proceedings/2009/papers/677/paper677.pdf

Shweder, R. A. (1999). Why cultural psychology? Ethos, 27, 62-73.

Smith, A. (1976/1759). The Theory of Moral Sentiments. Oxford: Oxford University Press.

Tetlock, P. E. (2003). Thinking the unthinkable: Sacred values and taboo cognitions. Trends in Cognitive Sciences, 7, 320-324. doi:10.1016/S1364-6613(03)00135-9

Waytz, A., Young, L. L., \& Ginges, J. (2014). Motive attribution asymmetry for love vs. hate drives intractable conflict. Proceedings of the National Academy of Sciences, 111, 1568715692.

Wetherell, G., Brandt, M. J., \& Reyna, C. (2013). Discrimination across the ideological divide: The role of perceptions of value violations and abstract values in discrimination by liberals and conservatives. Social Psychology and Personality Science, 4, 658-667. doi:10.1177/1948550613476096 
Wilson, T. D., \& Dunn, E. W. (2004). Self-knowledge: Its limits, value and potential for improvement. Annual Review of Psychology, 55, 493-518. doi:10.1146/annurev.psych.55.090902. 
Table 1. Results from bootstrapping mediation analyses, with political ideology predicting opinions, mediated through human coded fairness and sanctity verbal arguments (Studies $1 \&$ 3).

\begin{tabular}{|c|c|c|c|c|}
\hline & Without Mediators & & h Mediators & \\
\hline & \multirow[b]{2}{*}{$R^{2}$} & \multicolumn{2}{|c|}{ Indirect Effects, B [95\% CI] } & \multirow[b]{2}{*}{$R^{2}$} \\
\hline & & Fairness & Sanctity & \\
\hline Same-Sex Marriage & .22 & $-4.0[-6.8,-1.9]$ & $-7.1[-10.5,-4.1]$ & .68 \\
\hline Keystone Pipeline & .22 & $0.3[-0.3,1.3]$ & $2.2[1.2,3.7]$ & .30 \\
\hline
\end{tabular}

Note. Statistically significant indirect effects are in boldface. 
Table 2. The Modified Moral Foundations Questionnaire.

\begin{tabular}{|c|c|c|c|}
\hline \multirow[t]{2}{*}{ Foundation } & \multirow[t]{2}{*}{ Did the legalization of same-sex marriage... } & \multicolumn{2}{|c|}{ Slider Anchors } \\
\hline & & -100 & 100 \\
\hline Care & relieve or cause emotional suffering? (R) & Relieve & Cause \\
\hline \multirow[t]{2}{*}{$(\alpha=.82)$} & harm or protect the weak or vulnerable? & Harm & Protect \\
\hline & amount to an act of compassion or cruelty? (R) & Compassion & Cruelty \\
\hline Fairness & amount to the unfair or fair treatment of others? & Unfair & Fair \\
\hline$(\alpha=.88)$ & protect or deny the rights of others? $(\mathrm{R})$ & Protect & Deny \\
\hline Authority & respectful or disrespectful? (R) & Respectful & Disrespectful \\
\hline \multirow[t]{2}{*}{$(\alpha=.87)$} & dishonor or honor tradition? & Dishonor & Honor \\
\hline & amount to order or chaos? (R) & Order & Chaos \\
\hline Sanctity & undermine or promote standards of purity? & Undermine & Promote \\
\hline \multirow[t]{2}{*}{$(\alpha=.92)$} & tasteful or disgusting? (R) & Tasteful & Disgusting \\
\hline & desecrate or sanctify marriage? & Desecrate & Sanctify \\
\hline
\end{tabular}

Note: Reverse scored items denoted by (R). 
Table 3. Zero-order correlations with political ideology (conservatism). The relevance of sanctity in the morality of liberals versus conservatives depends on the issue at hand.

\begin{tabular}{llccc}
\hline & Care & Fairness & Authority & Sanctity \\
\hline Same-Sex Marriage (Study 2) & & & & \\
Effects & $-.63^{* * *}$ & $-.58^{* * *}$ & $-.64^{* * * *}$ & $-.65^{* * *}$ \\
Relevance & $-.31^{* * *}$ & $-.54^{* * *}$ & $+.28^{* * *}$ & $+.36^{* * *}$ \\
\hline Keystone XL Pipeline (Study 4) & & & & \\
Effects & $+.44^{* * * *}$ & $+.47^{* * * *}$ & $+.35^{* * * *}$ & $+.49^{* * *}$ \\
Relevance & $-.15^{*}$ & -.10 & $+.13^{\dagger}$ & $-.14 *$ \\
\hline
\end{tabular}

Note. ${ }^{\dagger} p<.10, * p<.05 ; * * * p<.001$ 
Running head: IDEOLOGICAL SYMMETRY

Table 4. Results from bootstrapping mediation analyses, with political ideology predicting moral opinions, mediated through

participants' perceived effects in terms of care, fairness, authority, and sanctity (Studies 2 \& 4).

\begin{tabular}{|c|c|c|c|c|c|c|}
\hline & Without Mediators & & & th Mediators & & \\
\hline & \multirow[b]{2}{*}{$R^{2}$} & \multicolumn{4}{|c|}{ Indirect Effects, B [95\%CI] } & \multirow[b]{2}{*}{$R^{2}$} \\
\hline & & Care & Fairness & Authority & Sanctity & \\
\hline Same-Sex Marriage & .52 & $0.7[-1.8,3.0]$ & $-5.1[-8.3,-2.9]$ & $-2.6[-6.8,1.0]$ & $-10.7[-14.7,-7.1]$ & .87 \\
\hline Keystone Pipeline & .26 & $3.1[1.0,5.8]$ & $3.7[1.6,6.5]$ & $1.7[0.6,3.2]$ & $2.3[0.2,4.7]$ & .73 \\
\hline
\end{tabular}

Note. Statistically significant indirect effects are in boldface. 
Running head: IDEOLOGICAL SYMMETRY

Table 5. Data-driven justifications for opinions on the Keystone XL Pipeline, their prevalence (hit rate), reliability, correlation with social conservatism, and independent mediating effect on explaining why liberals and conservatives disagree.

\begin{tabular}{|c|c|c|c|c|c|}
\hline Theme & Hit & $\%$ & $\kappa$ & $r$ with social & Mediation, B \\
\hline & rate & Agree & & conservatism & {$[95 \% \mathrm{CI}]$} \\
\hline Bring energy efficiently to consumers & $25 \%$ & $89 \%$ & .71 & $.28 * * *$ & $2.3[1.0,4.3]$ \\
\hline Improve foreign trade & $4 \%$ & $93 \%$ & .14 & - & - \\
\hline Create jobs & $23 \%$ & $97 \%$ & .91 & .13 & - \\
\hline Independent from the Middle East & $18 \%$ & $96 \%$ & .87 & $.28 * * *$ & $1.9[0.7,3.8]$ \\
\hline Reduce oil prices & $11 \%$ & $95 \%$ & .77 & .08 & - \\
\hline Stimulate the economy & $17 \%$ & $94 \%$ & .79 & .08 & - \\
\hline Business rights & $2 \%$ & $99 \%$ & .80 & .00 & - \\
\hline Protect the environment & $7 \%$ & $91 \%$ & .32 & - & - \\
\hline Environmental damage & $55 \%$ & $95 \%$ & .91 & $-.40 * * *$ & $4.9[2.7,8.0]$ \\
\hline Reduce jobs/ bad for economy & $5 \%$ & $93 \%$ & .24 & - & - \\
\hline Harm people & $10 \%$ & $98 \%$ & .89 & -.06 & - \\
\hline Encourage reliance on oil & $13 \%$ & $95 \%$ & .77 & $-.22 * *$ & $1.2[0.4,2.7]$ \\
\hline
\end{tabular}


Figure 1. Judges' ratings of the prevalence of fairness and sanctity in the justifications of opinions regarding same-sex marriage (study 1). Error bars represent 95\% CIs.

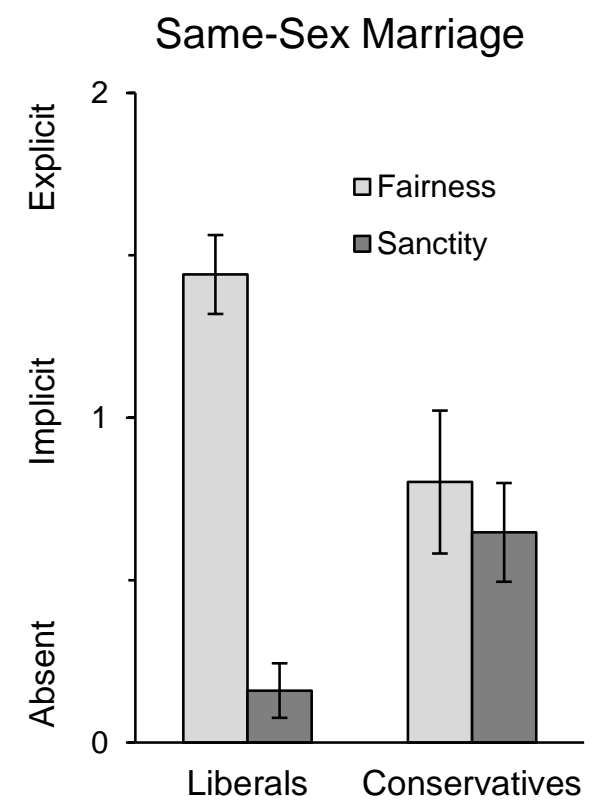


Figure 2. Close-ended, valenced moral justifications of opinions about same-sex marriage (study 2).

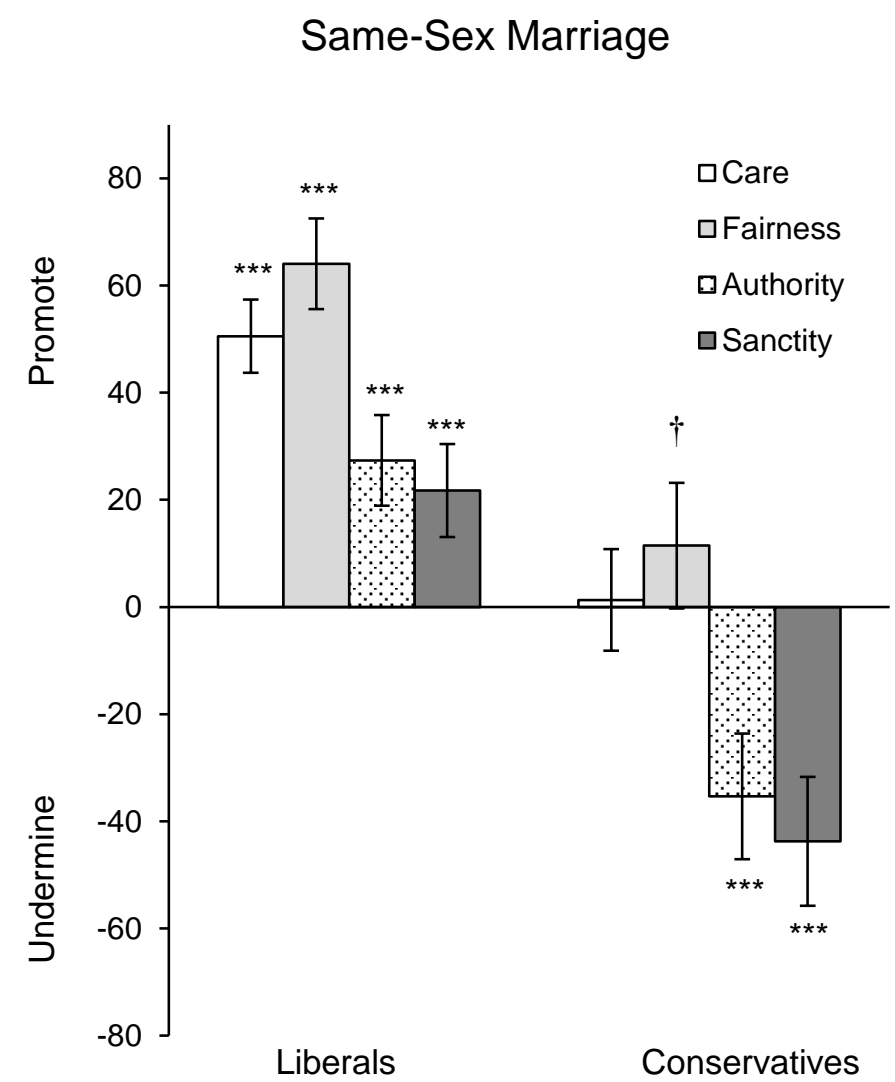

Note. Error bars represent $95 \% \mathrm{CIs} ;{ }^{\dagger} p<.10 ; * * * p<.001$; 
Figure 3. Judges' ratings of the prevalence of fairness and sanctity in the justifications of opinions regarding the Keystone XL Pipeline (study 3).

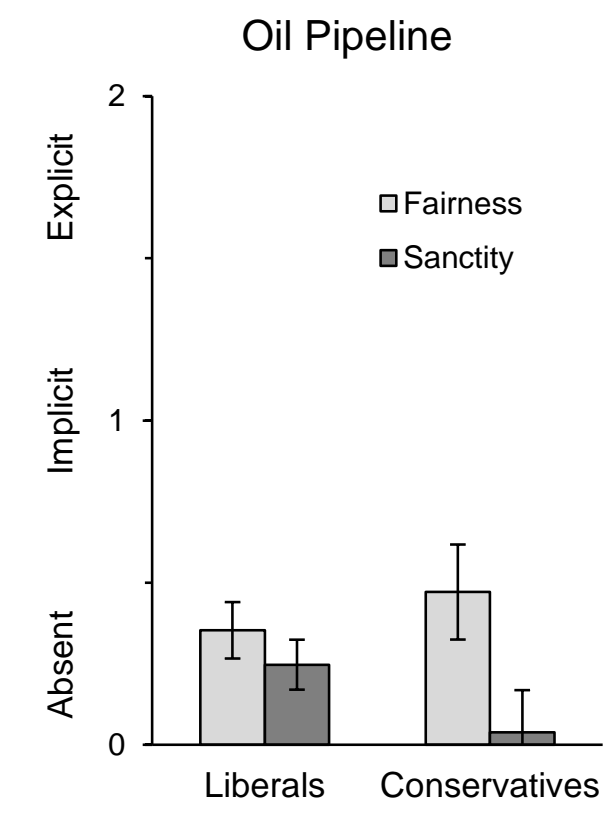

Note. Error bars represent 95\% CIs. 
Figure 4. Close-ended, valenced moral justifications of opinions about the Keystone XL

Pipeline (study 4).

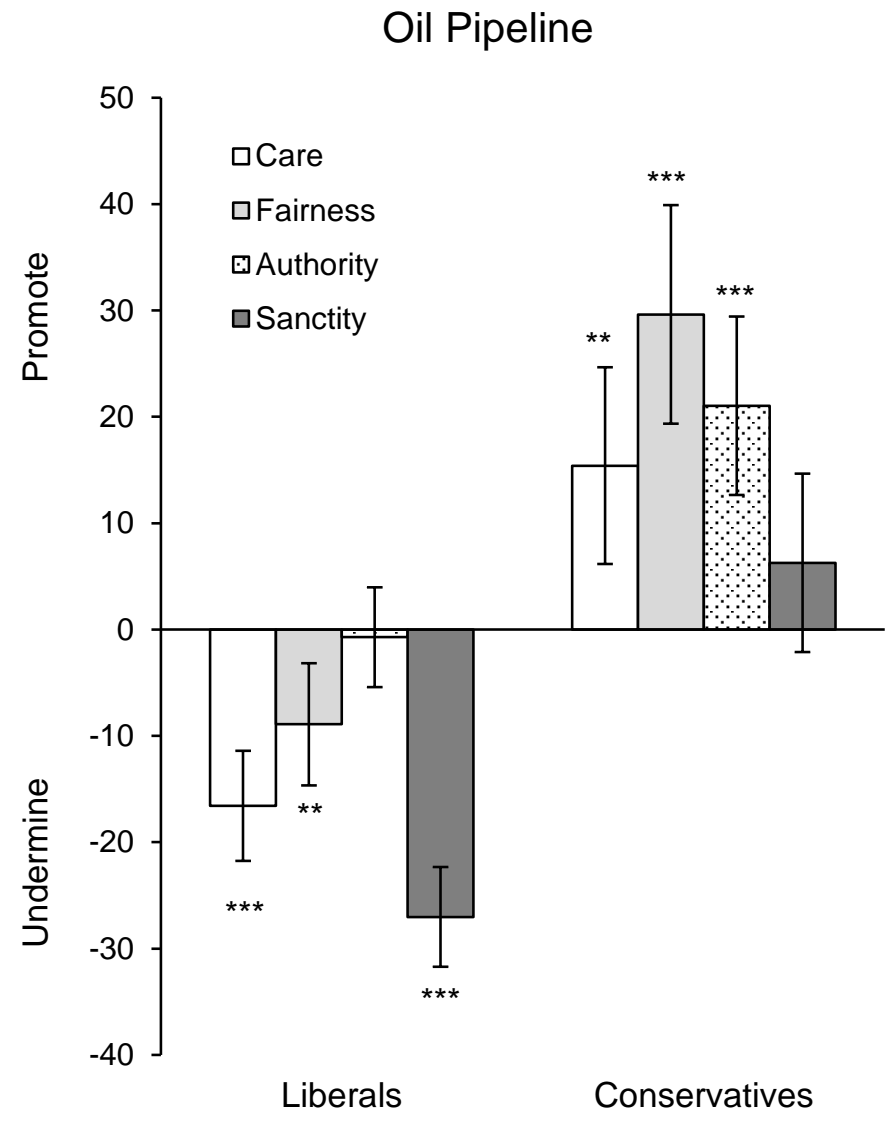

Note. Error bars represent $95 \%$ CIs; $* * p<.01 ; * * * p<.001$. 